\title{
AS RELAÇõES ENTRE HISTÓRIA E LINGÜÍSTICA A PARTIR DE ROBIN
}

\author{
Cleber Monticelli Petró
}

\begin{abstract}
RESUMO ${ }^{\circledR}$ : Este texto tem por objetivo trazer uma análise da leitura dos quatro primeiros capítulos da obra História e Lingüística de Régine Robin (1973), onde ela mostra as discussões teóricas a partir de autores diferenciados, além de ir esclarecendo o seu próprio ponto de vista quanto a uma teoria do discurso baseada na articulação dos conceitos da história e da lingüística. Pretende-se mostrar aos historiadores que a leitura de um texto traz problemas como a produção do sentido e que não se questionar sobre isso pode acarretar grandes equívocos interpretativos.
\end{abstract}

PALAVRAS-CHAVE: história, lingüística, década de 70.

\section{0 equívoco}

\subsection{A advertência}

Durante certo tempo, a lingüística esteve como mestra nas ciências humanas, impondo seus modelos e sua teoria do signo. A história estava em posição secundária, não sendo vista como possível de ser ciência, definindo-se por problemas apenas ideológicos. Em 1967, Mounin já criticava esse uso como sendo de moda e dizia "preferíamos que se utilizasse profunda mais solidamente a lingüística e que se precisassem bem as zonas em que ela se aplica" (p. 15-16). Robin (1974) coloca que não cabe ao historiador dar fim ao debate teórico dentro da própria lingüística, mas tirar o aprendizado com cautela, quanto ao uso dos conceitos emprestados. A autora passou a se questionar, quando foi estudar certos pedidos, e viu- se na dificuldade de dominar uma vasta documentação com os métodos temáticos dos historiadores. Então, apropriou-se da lingüística, porém apenas pedindo a esta disciplina um conjunto de processos de análise com a finalidade de facilitar seu trabalho. Mas, com o tempo, ela vê a necessidade de lutar contra um positivismo de quantificações e de pensar o que implicava o uso de certas teorias. Percebeu que

\footnotetext{
(c) Trabalho desenvolvido pelo aluno do $4^{\circ}$ semestre do curso de História- UFSM.
}

inicialmente estava evitando a relação do nível discursivo com as condições de produção do discurso. É a partir deste momento que vai dirigir seus estudos à enunciação, procurando maiores relações com as formações ideológicas, as formações discursivas, a teoria marxista, etc., que resultou em grande contribuição à formação do campo disciplinar da análise do discurso.

Para Robin, a lingüística permite substituir o dado do texto por uma lógica do texto. Serve apenas para revelar a economia interna de uma ideologia e não para estabelecer sua função social. A lingüística ordena a ideologia, não seu significado. A função de uma ideologia, sai do texto, passando da lingüística à história. $O$ que a autora propõe é que se peça ao lingüista como se ler o texto. A sua insistência neste aspecto é grande, pois muitos historiadores usam a lingüística e vêem nela, por ser formalizada, uma fonte de resultados incontestáveis. Esta forma de uso pode ser comparada com a que durante muito tempo, fez-se da estatística, na qual se procuravam dados e argumentos para combater a tese do materialismo histórico, uma vez que, por ser considerada "científica", obtinha grande respaldo. Ou seja, como já foi dito, a autora pretende, nesta obra, denunciar o positivismo empregado na análise, porém sem desmerecer a contribuição e a especificidade da lingüística.

\subsection{Língua e discurso}

A lingüística se constitui como ciência a partir de Saussure, e, neste momento, é feita a separação entre língua e fala, sendo que esta última não era muito observada pela disciplina. Atribuía-se a ela o domínio da liberdade, da individualidade, ficando sob o aspecto social apenas a língua. Esta separação traz a idéia de fala vinculada à psicologia do sujeito neutro, do "eu falo". Nesta separação mora o problema para o historiador, pois a este cabe estudar os fatos de fala que formam os discursos e não a língua como sistema.

A partir daí coloca-se uma pergunta: como definir um discurso? Guespin (Langages, n. 23, p.10) faz uma distinção entre enunciado e discurso, sendo que o discurso é o enunciado considerado do ponto de vista que 
o condiciona. Faz-se um estudo lingüístico das condições de produção. É encarado como processo.

Neste ponto o discurso é visto em torno de suas ligações com o extralingüístico, isto é, como prática. Isto não significa fazer da língua uma superestrutura. Ao mesmo tempo que não se nega a relação com a formação discursiva, da ideologia e da superestrutura, também não se quer reduzir a Análise do Discurso a uma sociologia do discurso (não se nega o nível lingüístico).

Segundo Robin (1973) procura-se constituir, no campo da história, o nível discursivo como novo objeto de estudo, orientando-se para uma problemática de articulação das práticas discursivas sobre práticas não-discursivas no seio de uma formação social.

A necessidade de incluir a ideologia no conceito de discurso foi constatada por pósformalistas russos, principalmente Medvedev, que, segundo Kristeva (La Nouvelle Critique, n.39, p.25), "propõe- se a formular o conceito de linguagem de maneira que possa ser ao mesmo tempo lingüístico e ideológico, como se exigirá de uma teoria que leve em consideração a história".

Após uma dezena de anos, elabora- se uma Lingüística do Discurso, estando na dependência do que se convencionou chamar de enunciação, como atitude do locutor diante de seu próprio discurso, como inserção do sujeito no interior de sua própria fala, como ato de produção do discurso. Para os lingüistas, este termo era meio duvidoso em relação ao seu campo, pois trazia consigo um mentalismo suspeito. De acordo com Todorov (Langages, n.17, p.3); "se se aceitar no momento que a enunciação é o ato individual da utilização da língua, enquanto que o enunciado é o resultado deste ato, podemos dizer que 0 objeto da lingüística atual é o enunciado e não a enunciação." A partir daí, podemos perceber o quão polêmica e difícil é a constituição de uma Lingüística do Discurso e de uma Análise do Discurso.

Courdesses(1971) mostra que, ao contrário da lingüística estrutural, em que o processo de enunciação tende a desaparecer no enunciado, o campo transformacional pretende teorizar a enunciação a partir de quatro conceitos básicos. O primeiro é o de distância relativa, colocada pelo sujeito entre ele próprio e o enunciado. O segundo é o de modalização que, segundo Wenrich, é a marca que o sujeito não cansa de dar ao enunciado. O terceiro é o de tensão, que diz respeito às relações entre o sujeito falante e o interlocutor. Por último o conceito de transparência ou opacidade, que aborda a marca da enunciação do ponto de vista do receptor. "Opacidade e transparência são constitutivos dos níveis de ambigüidade da mensagem" (Todorov).

Outra baliza à Lingüística do Discurso são as pesquisas de Ducrot trazendo à tona os pressupostos, as implicações e os subentendidos. "A linguagem natural não tem por única função a transmissão de informações. O simples jogo da linguagem instaura entre os indivíduos certas relações de colaboração, de luta, de domínio, de dependência." (Ducrot, 1966, p. 41). Para tal, o pressuposto é fundamental, sendo ele o conjunto de condições que devem ser preenchidas para que um enunciado seja lingüisticamente normal e para que a comunicação possa se estabelecer. É o que se apresenta como comum às duas personagens do diálogo (cumplicidade fundamental). Uma interlocução polêmica, por exemplo, surge da discordância de pressupostos e esta é mais do que desqualificar o enunciado, é desqualificar 0 ato de enunciação do qual ele procede. 0 pressuposto se apresenta como uma evidência, o que faz com que, muitas vezes, o interlocutor acabe vendo- se, contra a vontade, dentro de um pensamento, de um universo ideológico preciso.

A conotação é outro elemento fundamental à Lingüística do Discurso. Ela faz apelo ao código cultural ou ideológico de um país ou de uma classe. Como diz Hjelmslev, a linguagem é conotativa quando o significante já é uma linguagem, quando ele próprio comporta uma expressão (o significante) e um conteúdo (o significado).

Até este momento, descreveu-se como Robin traz elementos de autores diferentes que contribuíram à formação da Lingüística do Discurso, assim como deixa claro sua busca por uma teoria que se relacione com as formações discursivas, sendo estas, elementos das formações ideológicas

\section{As armadilhas da ausência de uma teoria da articulação}

\subsection{A lexicologia reduzida à sociologia}

Como primeira solução a esta busca Robin (1973) coloca a integração da lingüística à história ou a sociologia, retirando a autonomia do nível discursivo, fundindo- o no objeto da história social. Matoré parece ir neste caminho ao afirmar que "a lexicologia tem por objeto, como a Sociologia, o estudo 
dos fatos sociais ... É partindo do estudo do vocabulário que tentaremos explicar uma sociedade ... A lexicologia social pode ser vista como aquela que oferece não um objeto novo, mas um ponto de vista particular"( 1953, pg. 13).

Robin (1973) coloca que em vários estudos, pode-se substituir a sociologia pela história e que, segundo o próprio Matoré, a Lexicologia, quando tem por objeto o vocabulário das sociedades passadas, confunde- se com o objeto da história.

Esta relação com a história se faz necessária, pois só o estudo das palavras pode levar o historiador a não diferenciar entre discurso e comportamento. Não são as palavras que revelarão a verdadeira estrutura social, mas sim, com a ajuda de conceitos articulados, 0 estudo das relações de exploração ou dos modos de produção desta formação social. E, ao querer apagar esta autonomia do discurso, instala- se uma problemática ideológica.

\subsection{A palavra como índice de comportamento} político

Os historiadores sempre tiveram algum tipo de relação com a linguagem. Porém, empenhando a seguinte filosofia da linguagem: se é necessário buscar a significação do texto, busca- se o porquê na cultura e nas tradições, deixando a lingüística de lado.

O problema é que, como toda análise de material verbal emprega hipóteses da lingüística, que freqüentemente não é reconhecida como tal, o historiador mantém uma relação com a linguagem no sentido do postulado da evidência, da transparência da palavra, praticando um "caminho teórico encurtado"1. Dirigem atenção apenas ao léxico e não à semântica e à sintaxe.

Portanto, acabam trabalhando com a hipótese do isomorfismo entre os grupos sócio- políticos e o léxico, de forma que um grupo político seria caracterizado de acordo com o vocabulário que emprega.

Robin (1973) alerta que não pretende negar o lugar estratégico do léxico, porém este só pode ser considerado através de muitas mediações, tão complexo é o estatuto da palavra no discurso.

Segundo Marcellesi(1970) levar a sério esse isomorfismo é atribuir ao locutor uma dupla ingenuidade: lingüística e política. Pois, através destes elementos, o candidato, por exemplo, é capaz de manter diferentes discursos, variando- 0 de acordo com 0 universo enunciativo a que dirige a palavra, sendo esta ação denominada de mascaramento. As razões destas distorções devem ser procuradas na conjuntura, na base sociológica da circunscrição.

Outro isomorfismo que pode ocorrer é o que mistura prática política com prática discursiva, o que faz com que voltemos à problemática do sujeito neutro, do "eu falo". $\mathrm{Na}$ realidade, a palavra se encontra em uma proposição, e é isto que importa. "O que se postula então é uma relação entre uma estrutura sintática e um comportamento político. Não são as palavras, é a repartição das palavras no texto que implica um modelo ideológico subjacente" (Maldidier, 1971, p. 87 88).

\subsection{A sociolingüística}

A produção referente à sociolingüística gera uma série de discussões quanto à metodologia aplicada. A busca por um objeto fica em segundo plano.

Sapir (Langage, n 18, p.12-19) coloca a tônica na ligação entre a linguagem e o contexto cultural e social. Afirma que toda atividade lingüística implica pensar o uso de dois sistemas isoláveis: o referencial, que seria de domínio da lingüística da língua; e o expressivo, que compreende as manifestações ligadas à linguagem, tendo por objeto o discurso enquanto aspecto de comportamento. Desta forma cada língua passa a ser encarada como uma visão diferente de mundo.

Sapir (op. cit, p. 87) também adverte contra a visão que estabelece causalidade direta entre linguagem e cultura, pois, para ele, as mudanças lingüísticas e culturais não seguem o mesmo ritmo. Então teremos a etno ou sociolingüística como 0 estudo da mensagem lingüística em ligação com o conjunto das circunstâncias de comunicação, traçando o diálogo entre língua e mensagem lingüística de um lado e cultura do outro.

Robin (1973) faz um questionamento: como, então, relacionar um corpus escolhido, definido, limitado, com a totalidade de uma sociedade pensada em sua própria totalidade? Para ela, torna- se difícil buscar esta relação entre língua e cultura a não ser reformulando as idéias base de Sapir e Whorf na qual

\footnotetext{
1 as aspas são da própria autora
} 
os seres humanos não vivem 'unicamente no mundo objetivo, nem no mundo das atividades sociais, tal como se apresenta habitualmente, mas estão em grande parte condicionados pela língua particular que se tornou o meio de expressão de sua sociedade. É totalmente errôneo acreditar que nos adaptamos à realidade praticamente sem o intermédio da língua, e que esta não passa de um meio acessório para resolver problemas específicos de comunicação ou reflexão. A verdade é que o 'mundo real' está, em larga escala, inconscientemente edificado sobre os hábitos de linguagem do grupo... (1969).

Já Marcellesi propõe que se façam as descrições lingüística e sociológica de maneira paralela e, só ao final, tente- se estabelecer uma relação entre os modelos.

Apesar das contribuições da sociolingüística, Robin (1973, p.54) diz que ela dá acesso a uma descrição do discurso, mas não dá uma explicação a ele. Ao mesmo tempo em que dá certa autonomia do nível discursivo face às problemáticas redutoras que não questionam o problema do texto e escapa ao mecanismo que liga o discurso ao extralingüístico, continua com um grande problema teórico: os dois continuam paralelos. Não se pensa o estatuto de relação, não é pensado o lugar do nível discursivo político e suas determinações. Segundo a autora, o que impede essa relação é a herança da sociolingüística americana, puramente empirista, e que trabalha com justaposição de fatores sem hierarquia. Pelo que compreendi faz uma crítica também à visão puramente culturalista da língua, por ser muito generalizante, não dar conta, por exemplo, das disputas de classe dentro de uma mesma formação cultural.

\section{Os historiadores e o campo lingüístico}

\subsection{Análises temáticas e análises de conteúdo}

Um dos métodos empregados pelos historiadores é o de análise temática, onde se define- um domínio exploratório, dividindo- o em categorias temáticas. Este método não escapa da escolha pessoal, do recorte que o próprio pesquisador faz, sendo que, muitas vezes, nem se dá a explicação do porquê daquele recorte.

A análise de conteúdo é muito usada por historiadores da imprensa. É baseada na quantificação, na qual os estudos vão em busca de centros de interesse e como estes se desenvolvem ao longo do tempo.

"Quer se procure centros de interesse, temas, valores, palavras, o sentido é dado na leitura; deve- se então encontrar os princípios pertinentes de classificação, de hierarquização. (Robin, 1973).

Estes estudos negligenciam o nível discursivo enquanto tal, como se as ideologias não se revelassem também enquanto sistemas de representações nos discursos e como se a ordem do discurso, sua estrutura, não comportasse implicações ideológicas.

\subsection{Do vocabulário institucional ao vocabulário} ideológico

Quando o assunto é o vocabulário institucional e jurídico, há tempo que os historiadores trabalham com a ambigüidade e a polissemia no processo de análise, diferenciando-se das antigas leituras positivistas. Como exemplo, temos Marc Bloch, que em Apologie pour l'histoire, escreve contra os historiadores que ignoram as aquisições fundamentais da lingüística. Nesta nova forma de abordagem, este vocabulário é relacionado à ideologia e à forma como esta é construída em seu devido espaço temporal e formação social.

\subsection{De Lucien Febvre a Alphonse Dupront}

L. Febvre foi um dos historiadores que lutaram pela aquisição de outras disciplinas para renovação do campo histórico. Ele busca a lingüística de seu tempo, para formar uma história das palavras e das idéias. Esta lingüística não é a estrutural, que se firmará no cenário intelectual somente no fim de sua vida, mas é uma lingüística histórica, pré- estrutural. Não teve muita aproximação com os trabalhos de Saussure, que foram introduzidos tardiamente entre os lingüistas, ainda mais tarde entre os não lingüistas. O mais estranho, segundo Robin (1973, p.72), é que esse estudioso não tenha ouvido falar das pesquisas de Jakobson e Benveniste, do fonólogo Troubetzkoy, e a sua rejeição por Marx e Freud. O que Febvre procura é a origem das noções, sua evolução semântica em diacronia e o relacionamento com a história geral. A partir desta evolução, ele vai procurar uma espécie de síntese histórica, que se articula em uma estrutura mental. Como exemplo temos o seu estudo sobre a noção de civilização, na qual, para ele, esta nasceu na hora certa, ou seja, quando as condições de possibilidade se fixaram e quando ela exprime 
como que uma síntese de uma sincronia sociocultural precisa. Aqui nos deparamos com um paradoxo, pois apesar de não trabalhar com a lingüística estrutural, ao trazer novos domínios como sensibilidade coletiva, estrutura mental ele incorpora uma espécie de estudos estruturais não formalizados da interação dos diversos elementos do todo social: o estudo das rupturas ao lado do das continuidades e permanências.

Entre os continuadores de Febvre temos Duby e Mandrou. Também estes estavam envolvidos na questão do alargamento do campo histórico, em particular no que Febvre chamava de "aparelhagem mental".

Um dos grandes eixos de pesquisa de Duby era o estudo das representações que uma sociedade faz de si própria, o que 0 levava a dar ênfase às linguagens em todos os sistemas de signos que estão no âmbito de uma semiologia: rituais, iconografia, representações religiosas, etc e as suas evoluções e transformações, assim determinando mudanças de comportamento do homem perante o social e a vida real. $O$ primeiro instrumento de seus estudos é a linguagem, encarada como os diversos meios de expressão que o indivíduo recebe do grupo social em que vive e que servem de quadro a toda sua vida mental. Para ele, deve- se tirar proveito dos avanços da lingüística, principalmente da noção de campo semântico.

Mandrou traça um caminho diferente, por não estar tão centrado nas formações discursivas. Em primeiro plano estão as práticas e as ideologias nas práticas. Daí surgem duas noções: visão de mundo e comportamento, sendo que se fundem, devido ao fato de as visões de mundo serem materializadas no comportamento.

Já Dupront vai em busca de uma Semântica Histórica. Ele mostra a importância da linguagem e o quanto a historiografia analisou, visando o que ela dizia e não o que ela queria dizer. Vai além, critica a visão racionalista ligada à teleologia histórica por não dar atenção ao irracional, ao extraordinário, ao marginal, etc. Faz uma crítica a esta história continuísta, dizendo "Sabemos agora que o silêncio fala, mesmo que seja para impor a consciência do destruído e por conseguinte, para nos obrigar a diversificar as abordagens, a fim de atingir 0 vivido de um tempo"(1969, p. 29).

Como resposta a esta história continuísta, ele traz a lingüística, havendo nele um panlingüísmo que traz certos perigos. Esta autonomia da língua será postulada pela semântica histórica, sendo este o primeiro elemento impondo o estruturalismo com referências a Saussure, Troubetzkoy e Strauss.

Dupront substitui o modelo causal da historiografia pelo estudo da própria dinâmica das relações, o que significa que dá importância, antes de tudo, à análise interna de um texto e a sua rede de relações nocionais, introduzindo, para cada palavra, seu lugar e seu sentido. Utilizará como unidade de base a palavra, sendo esta conduzida ao "jogo da composição do conjunto" (Dupront, Langage et histoire, p. 27). Aqui toma referências a Troubetzkoy e através dele, à fonologia que tem por objeto passar do "estudo dos fenômenos lingüísticos conscientes ao de sua infraestrutura inconsciente" (1969, p. 27).

A língua passa a ser pensada em sua neutralidade ideológica, o que a autoriza a se refugiar por detrás do rigor, da objetividade da linguistica. A linguagem e o vocabulário passam a ser vias de sentido, onde todo texto é portador de uma ordem do mundo específica, de uma ordem a ser decifrada. Para tal análise, é necessário situar a palavra no tempo, levando em conta que esta emana de autores engajados em meios sociais precisos. Além deste corpus pertencer a uma dada língua em um momento preciso de sua evolução, o que faz com que não possa ser feita qualquer interpretação.

Robin (1973) afirma que, naquele momento, esta semântica histórica estava baseada na palavra e na quantificação. 0 próprio Dupront vê a limitação na falta de investigação quanto aos elementos reveladores de escolha, do implícito. No início a Semântica Histórica era uma história linear do signo.

Dupront propõe que se parta para buscar o campo nocional, o vocabulário dominante. Após isto, construir uma constelação- imagem que determine o valor dos hábitos estabelecidos e que, com a noção de "tema" renovada, revele a regularidade discursiva fundadora de uma nova ordem ideológica e afetiva que geralmente escapa ao historiador que só busca na evidência. Esta análise permitiria- nos perceber aproximações em estudos diferentes, não no conteúdo, mas na imagem, onde conteúdos contraditórios podem revelar uma ordem do discurso comum, uma profundeza na qual esteja o que Dupront chama "o sentido".

Este autor gosta do método estatístico, mas sabe dos seus limites. Percebe- se na sua citação: "O corpus estatístico, objeto em si 
morto, só se anima pela interrogação de uma problemática. A orientação da pesquisa provoca a resposta, sem nunca condicionála..." (Dupront. Obra. citada, p. 31).

Além do mais, ele retém três aspectos básicos da psicanálise: linguagem como via do inconsciente, inconsciente coletivo e técnicas de análise. Refere-se a Freud, Lacan, mas também a Ricoeur e a Yung. Retorna à problemática consciente/inconsciente, distinção e coexistência de dois universos, um do mundo e outro da alma profunda. Acredita num além discurso que contém as raízes do sentido, e é aí que mora a contradição do seu pensamento, pois sua psicanálise toma formas de hermenêutica. Trata- se de uma contradição, visto que é justamente este sentido que Marx, Freud e Nietszche destroem colocando em seu lugar o sentido construído. Ou seja, Dupront fica preso entre uma problemática materialista e uma criacionista.

Para Robin a inversão de Freud não acaba com a sua abordagem textual, além do que sua Semântica Histórica foi importante para fazer da estrutura lingüística um novo objeto da historiografia contemporânea. Ela termina este capítulo apontando para um momento de incertezas, de insegurança, mas também de renovação e através de suas colocações (feitas no início dos anos 70) que ela se propõe e acredita no que naquele período ainda estava engatinhando, que era a tentativa de relacionar psicanálise e marxismo.

\section{Formação discursiva, prática discursiva e ideologia}

4.1. As insuficiências da Lingüística do Discurso

Robin (1973) coloca que a lingüística vivia momentos de revisões fundamentais. Apesar do avanço com os conceitos de conotação e enunciação, por exemplo, estes pareciam estar, algumas vezes, presos à problemática língua/fala. Outro grande avanço foi a visão processual da enunciação, trazida pelos transformacionistas, mas mesmo assim ainda persistia uma flutuação que consistia em colocar o problema da enunciação ora em termos de processo, ora em termos de marca de uma enunciação já dada.

Outra discussão se dava em torno de onde começa e onde termina a enunciação. $O$ Ducrot (Langage, n.17) situa assim o problema: "É preciso distinguir os fenômenos ligados à enunciação, e a intervenção do sujeito da enunciação na construção da significação". Porém, Robin faz um questionamento a esta formulação e pergunta se há realmente a possibilidade desta separação, ou se a significação não deve sempre estar ligada às condições de produção do discurso e às formas de intervenção do locutor, inclusive na escolha entre as unidades lexicais usadas.

Também pergunta se 0 termo enunciação não designa, de forma empírica, o lugar que ocuparia a noção de "sistema de representações" 2 ligada à noção de ideologia, no materialismo histórico.

Propõe que se trabalhe com a interdisciplinaridade e que como coloca Tort (artigo, pg.146), não se pode esperar que o confrontamento entre o nível lingüístico e o histórico traga uma resposta definitiva às questões, mas se deve partir das margens onde estão em disputas as disciplinas, sem mexer no centro de cada uma.

4.2. Michel Foucault e a constituição do objeto discursivo

4.2.1. As condições de possibilidade do
discurso

Foucault (1969) não tem como centro de suas pesquisas o discurso, não é baseada no referente. Ele não procura saber o que é a loucura e depois como é encarada pelos discursos ao longo do tempo. Seu objeto não está nas coisas, nem nas palavras, mas é constituído pelas condições de possibilidade de um discurso, o campo problemático que faz com que exista um discurso e não outro. Estas condições de possibilidade estariam inscritas no próprio discurso, pois estas condições que o aprisionam não seriam exteriores a ele, mas se localizariam no limite do discurso, oferecendo- the objetos de que ele possa falar. Este campo de configuração resulta no que ele chama de formação discursiva.

$\mathrm{Na}$ obra Naissance de la clinique (1963) ele fala de "mutações dos discursos", passagem de uma forma enunciativa a outra, sendo que centraliza as modificações na linguagem, onde percebe o discurso racional sobre a doença. Nota, então, uma nova organização dos elementos que constituíam a antiga teoria, uma nova organização do espaço perceptivo.

Desta forma, a busca de Foucault é o que torna este ou aquele discurso possível, e o discurso será o conjunto dos enunciados

\footnotetext{
2 as aspas são da própria autora
} 
enquanto no âmbito de uma mesma formação discursiva. Isto obriga Foucault a colocar o problema da emergência das práticas não discursivas dentro do próprio discurso, sendo este encarado como prática. Ele postula a não autonomia do discurso, porém apresenta esta relação a nível de justaposição, sem um, determinante, sem jamais estar relacionado ao conjunto de uma formação social.

\subsubsection{O objeto discursivo em L'Ordre du discours}

Em uma aula inaugural no Collège de France em 1970 aparece em Foucault o discurso como tal. Por exemplo, na questão do discurso sobre a sexualidade, ele se propõe a analisar conjuntos literários, médicos, éticos em torno deste problema.

Desta forma, ele vai tirar do centro da pesquisa as formações discursivas para observar as pluralidades de séries e as descontinuidades existentes, ou seja, vai investigar como as interdições não funcionam da mesma maneira nos diversos discursos, e como se dão os deslocamentos de dominância discursiva( por que em determinado momento predomina um discurso religioso e em outro o econômico?). Aqui Robin (1973, p.97) coloca uma provocação: "não seria necessário procurar a razão dos deslocamentos nos AIE (Aparelhos Ideológicos de Estado) da formação discursiva?"

Esta abordagem pluriserial é encontrada também nas primeiras obras de Foucault, sendo mais centrada no discurso, porém colocando como menos central a relação entre práticas discursivas e práticas não discursivas.

Além destas contribuições vistas até o momento, este autor foi um grande opositor da hermenêutica do sentido que não considera as condições de produção do discurso.

Segundo Robin (1973), as obras de Foucault deixam os intelectuais um pouco impotentes para trabalharem a relação entre prática discursiva e prática não discursiva, devido a não falar nos conceitos do materialismo histórico. Assim como torna difícil refletir sobre a formação do objeto discursivo pela ocultação que faz da estrutura lingüística do discurso.

4.3. Alguns trabalhos recentes de historiadores e a contribuição do objeto discursivo

Gutton estuda a pobreza e a visão da pobreza de 1534 a 1789, Lebrun, a morte e as atitudes diante da morte em Anjou nos séculos
XVII e XVIII. Estas duas obras abordam em forma temática, recorrendo a múltiplas fontes onde se possa encontrar referências ao tema central. Lebrun observa que, no fim do século XVIII, desenvolve-se uma estrutura mental que é reveladora. Enquanto a morte real (demográfica) não se modifica, as atitudes diante dela mudam. Assim como Gutton mostra que no final do século XVIII não se é mais hostil aos mendigos por moral ou costumes, mas por motivos econômicos e de ordem pública. As transformações econômicas e sociais não modificam 0 mundo dos mendigos. As duas obras são semelhantes no sentido de uma parte falar da realidade objetiva e outra das atitudes perante esta realidade. Segundo Robin, esta não mistura é interessante, mas não satisfaz os interesses que buscam um diálogo interdisciplinar pois,: ao analisar certas fontes, não leva em conta a organização da estrutura lingüística. As rupturas constatadas acabam sendo de conteúdo e não discursivas. Assim sendo, a linguagem não se constitui como objeto da disciplina histórica. A segunda diz razão à causalidade específica que poderia explicar o porquê das mutações. Nenhum dos livros coloca o que explica essas mutações.

\subsubsection{Michel Vovelle e as fórmulas} testamentárias

A sua intenção é quantificar ao nível social, as atitudes diante da morte, assim como a evolução destas, procurando rupturas mais importantes. Diferencia-se das obras de Gutton e Lebrun por três motivos: a busca das atitudes constitui o objeto, o aparelho das fontes não é por tema, mas por uma única fonte privilegiada, no caso, os testamentos e devido a levar em consideração a estrutura lingüística do texto, uma vez que é na mudança do tipo de discurso constituído pelo testamento que o autor vai inferir a ruptura da sensibilidade religiosa. Acaba introduzindo a possibilidade de utilização de métodos lingüísticos pelo historiador.

\subsection{Esboços de alguns conceitos do} materialismo histórico

Para o materialismo histórico, uma formação social é constituída de vários modos de produção, ou da coexistência de formas provenientes de diversos modos de produção e reestruturadas em função da dominância de um destes modos. Marx diz que o econômico predomina em sua época, mas que em outros momentos predominaram o político, o religioso, etc.. Porém esta dominância sempre 
está relacionada com a base material desta sociedade. Para a manutenção de um modo de produção, são necessárias relações pessoais de dependência. No caso do período medieval, por exemplo, há um domínio combinado do jurídico e do religioso que as regula e as articula sobre a ordem divina. 0 estudo destas relações se baseia na análise da luta de classes e seus efeitos. Sobre a questão do determinante, Engels coloca que ele e Marx afirmam que o fator determinante é, em última instância, a produção e a reprodução da vida material. Ele adianta possíveis interpretações que coloquem o fator econômico como único determinante. Esta passagem coloca que as ideologias têm uma determinação mais complexa em sua forma que em sua função.

T. Herbert faz uma distinção (que de acordo com Robin ainda estava em discussão naquele momento). Divide a ideologia em duas formas: uma, empirista, refere-se ao processo de produção, reorganiza os elementos do processo de trabalho, fascinado pela realidade, há um ajustamento entre significação e realidade. Esta forma dominaria os comportamentos, as palavras. A outra é a forma especulativa, onde a ideologia é referente às relações sociais de produção, trata-se da forma fraseológica, tem como função a de mostrar aos agentes seu lugar nas relações de trabalho, visa à racionalização que permite que o sujeito se identifique com as estruturas políticas e ideológicas, e que lhe dê a ilusão de que ele é a origem de suas idéias, de sua subjetividade. Esta forma dominaria o nível dos discursos.

Herbert insiste no fato de que nunca encontramos o ideológico como tal, mas formações ideológicas que diferem segundo a formação social.

Segundo Robin (1973, p.114) quatro traços podem caracterizar a ideologia:

- Não são arbitrárias, mas orgânicas, são historicamente necessárias para a organização das massas;

- Tem função específica numa formação social. Elas deslocam as contradições reais das sociedades e segundo $\mathrm{N}$. Poulantzas "reconstituem num plano imaginário um discurso relativamente coerente que serve de horizonte ao vivido dos agentes" (1969, pg. 224), tem um lugar na estrutura de classes e na própria luta de classes;

- Uma ideologia é inconsciente de suas próprias determinações, de seu lugar numa luta de classes. É inconsciente de sua coerência e organização;

- Ela tem uma existência material. O que Althusser, seguindo Gramsci sugeriu se chamasse de AIE (Aparelhos Ideológicos do Estado).

Dando seqüência à questão do Estado, pode-se concluir que as contradições de classe necessitam de um poder de Estado que represente os interesses fundamentais da classe dominante. Este Estado é, então, enxergado (ilusoriamente) como que acima das classes, portanto, neutro perante as relações sociais. Mas este quadro de relações não pode ser visto de forma mecânica. As descontinuidades entre a base econômica e o poder do Estado, entre os aparelhos ideológicos do Estado e a economia, na medida que os AIE tem temporalidade própria podem ser reintroduzidos por outras práticas ou discursos.

Baseado nesta idéia de Estado neutro, tem-se a conclusão de que, através dos AIE, transmite-se uma linguagem universal, na aparência. Esses meios reproduzem a real divisão das relações de produção, porém ao nível discursivo e ideológico. Mas isto não quer dizer que o poder do Estado consiga reproduzir automaticamente sua visão ideológica, consciente ou inconscientemente, de forma automática, pois se assim fosse estaríamos negando a própria luta de classes e as contradições de uma formação social.

\section{CONCLUSÃO}

Após ter-se apresentado um pouco da evolução das discussões na formação do que hoje se conhece como Análise do Discurso, a partir do livro História e Lingüística (1973) de Régine Robin, pode-se perceber um pouco do momento em que este se insere. A autora, que escreve o livro no início dos anos 70, procura criticar os estudos que tendiam a separar 0 discurso e a construção do seu significado das suas condições de produção. Entende-se que a sua proposta é de dar seguimento a uma teoria das ideologias vinculada às relações de produção, pois assim saberemos como e porque 0 sujeito identifica-se com certos discursos e a partir do que ele faz suas escolhas cotidianas.

O objetivo do livro não é esgotar as discussões, mas apresentar o que para a autora constituía até aquele momento um problema: o fato de ainda não haver uma 
teoria do discurso que conseguisse fazer a articulação entre história e lingüística.

\section{REFERÊNCIA BIBLIOGRÁFICA}

Robin, R.(1973) História e Lingüística. Trad. Editora Cultrix Ltda. São Paulo. 